\title{
Quantification of Lipid Content and Identification of the Main Lipid Classes Present in Microalgae Extracts Scenedesmus sp. for Obtaining Fatty Compounds for Biofuel Production
}

\author{
Carolina Vieira Viegas', Leonardo Brantes Bacellar Mendes², Rafael Richard João², \\ Gisel Chenard Díaz ${ }^{1}$, Donato A. G. Aranda', Yordanka Reyes Cruz ${ }^{1}$ \\ ${ }^{1}$ GREETEC Laboratory, Federal University of Rio de Janeiro (UFRJ), Rio de Janeiro, Brazil \\ ${ }^{2}$ CENPES/PETROBRÁS_Leopoldo Américo Miguez de Mello Research Center, Rio de Janeiro, Brazil \\ Email: carolquimica@gmail.com
}

How to cite this paper: Viegas, C.V., Mendes, L.B.B., João, R.R., Díaz, G.C., Aranda, D.A.G. and Cruz, Y.R. (2020) Quantification of Lipid Content and Identification of the Main Lipid Classes Present in Microalgae Extracts Scenedesmus sp. for Obtaining Fatty Compounds for Biofuel Production. Energy and Power Engineering, 12, 273-287.

https://doi.org/10.4236/epe.2020.126017

Received: May 11, 2020

Accepted: June 9, 2020

Published: June 12, 2020

Copyright $\odot 2020$ by author(s) and Scientific Research Publishing Inc. This work is licensed under the Creative Commons Attribution International License (CC BY 4.0).

http://creativecommons.org/licenses/by/4.0/

\section{(c) (i) Open Access}

\begin{abstract}
Microalgae biomass has been reported in the literature as one of the most promising sources for obtaining different products of industrial interest such as lipids, fatty acids, carotenoids, proteins and fibers. The lipid fraction of microalgae comprises neutral lipids, free fatty acids and polar lipids. It is of great importance to estimate the composition of the lipid fraction to define the potential for use, either as a raw material for the production of biofuels or for use for nutraceuticals and/or food purposes. The microalgae Scenedesmus sp. cultivated in a photobioreactor, the sky open raceway type, was evaluated for lipid content, identification and quantification of lipid components obtained from different extracts. In the quantification of the lipid content, extraction methods were proposed without chemical treatment (use of solvents only) such as chloroform:methanol (2:1 v/v) -Bligh \& Dyer, Ethanol, Ethyl acetate:Hexane $(1: 1 \mathrm{v} / \mathrm{v})$ and others with chemical treatment such as J-Schmid-Bondzynski-Ratzlaff (acid) and saponification (basic). For the identification of the main lipid components present in the extracts, the Thin layer chromatography (TLC) technique was used. This made it possible, using a simple and inexpensive method, to identify the compounds extracted by different extraction methods, that is, it was possible to verify the selectivity of the different extraction methods. In addition, it has been shown that using these methods, widely described in the literature as methods of extracting lipids in practice, extracts a wide diversity of compounds. The levels of lipids obtained via solvent extraction were up to $50 \%$ higher than those obtained
\end{abstract}


with chemical treatment. In lipid extracts, obtained via solvent extraction, the presence of polar compounds, glycerides, carotenoids, pigments and sterols was identified, with up to $53 \%$ being composed of an unsaponifiable fraction, thus, presenting low selectivity for extracting fatty components. The acidic and basic treatments applied to the biomass of Scenedesmus sp. showed greater selectivity for obtaining fat components of $71.47 \%$ and $94.99 \%$, respectively. The results showed that depending on the solvent/method used to quantify the lipids, the selectivity for obtaining the grease fraction, fundamental for conversion into biofuels, varies and the total lipid content may be overestimated.

\section{Keywords}

Microalgae, Lipids, Extraction, Saponifiable Compounds, Biofuels

\section{Introduction}

To develop large-scale microalgae cultivation, it is necessary to isolate and characterize the species, improving the genetic tools in search of specific characteristics. For example, in the cultivation of microalgae, some factors can influence the production of lipids such as: $\mathrm{pH}$, concentration of nutrients, light intensity and temperature [1] [2] [3] [4]. These environmental conditions can be controlled and the species selected according to the desired fatty acid(s) [5].

The term "biomass" means any organic matter that is available on a recurring or renewable basis including, plants, agricultural waste, aquatic plants, wood and wood waste, animal waste, municipal waste and other waste used for industrial energy production, fuels, chemicals and materials [6] [7] [8].

An emerging alternative is the use of aquatic biomass; it is estimated that the global primary production of biomass is $50 \%$ aquatic and $50 \%$ terrestrial. To this day, government policies have focused almost exclusively on the use of terrestrial biomass, paying little attention to aquatic crops, taking as examples macro and microalgae [9]. Marine microalgae are prokaryotic or eukaryotic photosynthetic microorganisms that can grow quickly due to their ability to convert $\mathrm{CO}_{2}$ and transform into proteins, carbohydrates and lipids [1] [10] [11].

Currently, countries with emerging economies like China and India are working on the development of technologies for the production and commercialization of microalgae biodiesel, aware that the current sources have not supplied the energy required for planned economic growth [12] [13]. The cultivation of microalgae for the production of biomass is widely accepted as a probable ecocompatible option for the generation of biofuels.

The term "lipid" is broad, as it includes a highly diverse group of molecules with similar solubility in organic solvents. As will be discussed in this article, only some of these lipids are suitable for the production of biofuels, while others are potentially valuable in terms of nutrition [14] [15]. In the microalgae differ- 
ent lipid classes are found, their composition and fat profile can vary greatly between different species and also according to the culture conditions. Therefore, knowledge of the lipid composition of microalgae is crucial for the selection of an appropriate extraction solvent and for the definition of the technological route to be applied in the production of biofuels [16] [17]. Specifically for this purpose, a distinction should be made between saponifiable and unsaponifiable lipids [18]. Saponifiable molecules are those that include at least one grease chain in their structure, which can be converted into soap from the saponification process and later into fatty acid [19].

Unsaponifiable lipids are all remnants that do not contain an acyl chain and therefore cannot be converted into soap. Some examples of unsaponifiable lipids are wax esters, pigments (chlorophylls, carotenes, etc.), sterols and hydrocarbons [3] [20]. The term "total lipids" is used primarily for analytical purposes, in addition to acylglycerols, the crude lipids obtained from microalgae often contain free fatty acids, hydrocarbons, ketones, sterols, carotenoids and chlorophylls [16]. For this reason, the crude lipid extract obtained from microalgae is often subjected to more than one fractionation step before being transesterified [21] [22]. The detection, identification and precise quantification of lipid compounds are prerequisites for verifying the potential of each species of microalgae in the production of target compounds. For this purpose, the Thin Layer Chromatography (TLC) technique is used [23] [24] [25]. Method simple and inexpensive allows identifying the compounds extracted by different extraction methods, to verify the selectivity of the different extraction methods. In addition, the use of these methods, widely described in the literature as methods of extracting lipids in practice extracts a wide diversity of compounds. The main contribution of this study is to define what types of compounds can be extracted by each method to be used depending on the application.

The objectives of the present work were to provide data on the variation of the lipid content in relation to the solvent/method used to extract the lipids, as well as the composition of the lipid classes and composition of unsaponifiables (including sterols and hydrocarbons) of the microalgae Scenedesmus sp. aiming at a more selective extraction of fatty compounds [16] [26].

\section{Materials and Methods}

The biomass of Scenedesmus sp., provided by UFRN (Federal University of Rio Grande do Norte), was grown for 5 days in an open Raceway photoborractor with a volume of $5.000 \mathrm{~L}$ (Figure 1), using 30\% PP medium. Growth monitoring was performed by optical density, as described by Lee [27], making absorbance readings at wavelengths of $680 \mathrm{~nm}$ and $750 \mathrm{~nm}$ every day. At harvest, the cultivation was transferred to a settling tank and $2.5 \mathrm{ppm}$ of cationic polyacrylamide flocculant was added until biomass reached approximate concentration of 10 $\mathrm{g} \cdot \mathrm{L}^{-1}$. Subsequently, the concentrated material was centrifuged at a speed of 5000 $\mathrm{rpm}$ to obtain a microalgae concentrate of $45 \mathrm{~g} \cdot \mathrm{L}^{-1}$. 


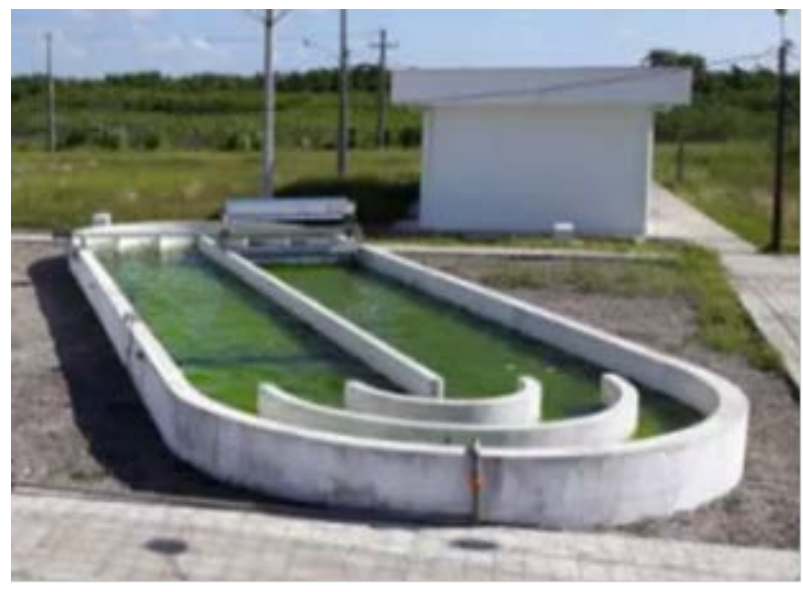

Figure 1. Cultivation of Scenedesmus sp. in raceways at UFRN.

The biomass of Scendesmus sp. centrifuged (10 minutes, $5000 \mathrm{rpm}$ ) was oven dried at $70^{\circ} \mathrm{C} \pm 1{ }^{\circ} \mathrm{C}$, ground in a knife mill to reduce the particle size and subjected to different procedures for quantifying lipids. In the extraction of the lipid fraction, methods were used that differed in terms of the use of solvents and the chemical treatment with the use of solvents applied to biomass. For the extraction of lipids the solvents were evaluated: Chloroform: methanol 2:1 v/v (Bligh and Dyer), Ethanol and Ethyl acetate: hexane $(1: 1 \mathrm{v} / \mathrm{v})$. In addition, an acid treatment was applied to the biomass by the J:Schmid-Bondzynski-Ratzlaff method and basic by the "in situ" saponification method to obtain the fatty components.

\subsection{Lipid Extraction-Solvent Evaluation}

\subsubsection{Solvent 1—Bligh \& Dyer-Chloroform:Methanol (2:1 v/v) [28]}

Extractions were performed in a $50 \mathrm{~mL}$ flask, starting from $5 \mathrm{~g}$ of dry biomass with $15 \mathrm{~mL}$ of the mixture chloroform: methanol $(2: 1 \mathrm{v} / \mathrm{v})$, following the methodology described in the literature [2] [29] [30] [31]. A solvent: charge ratio of 3:1 ( $\mathrm{mL}$ of solvent: $\mathrm{g}$ of biomass), extraction time of 2 hours at a temperature of $60^{\circ} \mathrm{C}$ and $200 \mathrm{rpm}$ stirring on a magnetic stirrer were used. For the separation of residual biomass from the liquid phase (lipid fraction + solvent), a filter paper filtering process was carried out. Then the biomass was washed with $30 \mathrm{~mL}$ of the solvent mixture selected for the extraction step and filtered again. The solvents were removed from the liquid phase by vacuum evaporation and the lipid fraction (not volatile under operating conditions) was dried to constant weight in an oven at $60^{\circ} \mathrm{C}$. The experiments were carried out in triplicates and the extraction yield was determined in percentage, in relation to the dry biomass mass.

\subsubsection{Solvent 2 -Ethanol}

In order to exhaust all the grease fraction present in the microalgae biomass, the Sohxlet extraction technique was used, performed through successive washes of the biomasses from the continuous cycle of evaporation and condensation of the organic solvent. This cycle was repeated until the total removal of crude lipids 
[2]. To do this, 10 grams of the dry biomass of microalgae, stored in a cellulose cartridge, inserted inside the Soxhlet apparatus, and $200 \mathrm{~mL}$ of ethanol were added in the balloon located at the bottom of the equipment, which was subsequently heated to approximately $80^{\circ} \mathrm{C}$ for 2 hours. The flask containing the solvent and the solubilized content was taken to a rotary evaporator in order to recover all the solvent, and then to an oven at $60^{\circ} \mathrm{C}$ until constant weight. The experiments were carried out in triplicates and the extraction yields were determined as a percentage, in relation to the dry biomass mass free of ash.

\subsubsection{Solvent 3-Ethyl Acetate:Hexane (1:1 v/v)}

The extractions were carried out in a $50 \mathrm{~mL}$ flask, starting from $5 \mathrm{~g}$ of dry biomass with $15 \mathrm{~mL}$ of the mixture Ethyl acetate: hexane (1:1 v/v). A solvent: charge ratio of 3:1 ( $\mathrm{mL}$ of solvent: $\mathrm{g}$ of biomass), extraction time of 2 hours at a temperature of $60^{\circ} \mathrm{C}$ and $200 \mathrm{rpm}$ stirring on a magnetic stirrer were used. For the separation of residual biomass from the liquid phase (lipid fraction + solvent), a filter paper filtering process was carried out. Then the biomass was washed with $30 \mathrm{~mL}$ of the solvent mixture selected for the extraction step and filtered again. The solvents were removed from the liquid phase by vacuum evaporation and the lipid fraction (not volatile under operating conditions) was dried to constant weight in an oven at $60^{\circ} \mathrm{C}$. The experiments were carried out in triplicates and the extraction yield was determined in percentage, in relation to the dry biomass mass.

\subsection{Lipid Extraction-Chemical Treatment of Biomass}

\subsubsection{Acid Treatment-J:Schmid-Bondzynski-Ratzlaff [32]}

The extraction was performed starting from $5 \mathrm{~g}$ dry biomass-in a $50 \mathrm{~mL}-10$ $\mathrm{mL} \mathrm{HCl} 8 \mathrm{M}$ falcon tube; Hydrolysis: 10 minutes water bath at $60^{\circ} \mathrm{C} ; 1^{\text {st }}$ Extraction: $10 \mathrm{~mL}$ absolute ethanol; $25 \mathrm{~mL}$ ethyl ether; $25 \mathrm{~mL}$ petroleum ether; Separation of the phases in a funnel. $2^{\text {nd }}$ and $3^{\text {rd }}$ Extraction: $10 \mathrm{~mL}$ absolute ethanol; 25 $\mathrm{mL}$ ethyl ether; $25 \mathrm{~mL}$ petroleum ether; Washing of the "solvent" phase with distilled water until $\mathrm{pH}$ of the water $=7$ (to remove $\mathrm{HCl}$ residues); Evaporation of the solvent; Kiln drying at $60^{\circ} \mathrm{C}$.

\subsubsection{Basic Treatment-Saponification "In Situ"}

Saponification "in situ" was carried out by mixing $5 \mathrm{~g}$ of dry biomass with $50 \mathrm{~mL}$ of hydroalcoholic solution $(20 \% \mathrm{KOH}$ in $95 \%$ alcohol $\mathrm{m} / \mathrm{v})$ in an oil bath under $200 \mathrm{rpm}$ magnetic stirring, for 1 hour at $60^{\circ} \mathrm{C}$. After the reaction was completed, the sample was vacuum filtered to remove residual biomass. The saponification product, still hot, was transferred to a separating funnel and, after reaching room temperature, $50 \mathrm{~mL}$ of the hexane:water solution (70:30) was added and the funnel was vigorously stirred. The fraction saponifiable (lower phase), from saponification, a stoichiometric molar amount of $\mathrm{H}_{3} \mathrm{PO}_{4}$ was added, thus obtaining fatty acids. The reverse reaction (soap-fatty acid) was carried out under magnetic stirring at $200 \mathrm{rpm}$ at $70^{\circ} \mathrm{C}$. After the reaction time of 1 hour, the sample was transferred to a separating funnel, separating the fatty acids with the addition of 
$2 \times 50 \mathrm{~mL}$ of hexane. The hexane fraction, containing the fatty acids, was washed with $2 \times 15 \mathrm{~mL}$ of water to remove the remaining salt. The solvents were removed from the liquid phase by vacuum evaporation and the lipid fraction (not volatile under operating conditions) was dried to constant weight in an oven at $60^{\circ} \mathrm{C}$. The experiments were carried out in triplicates and the extraction yields were determined in percentage, in relation to the dry mass.

\subsection{Identification of Lipid Components-Thin Layer Chromatography (TLC)}

In the identification of the lipid classes of interest, present in the extracts of the microalgae Scenedesmus sp., was used the modified method of Thin layer chromatography (TLC). In this analysis, $0.001 \mathrm{~g}$ of the extracted lipid fraction was dissolved in $600 \mu \mathrm{l}$ of chloroform. The equivalent of $0.03 \mu \mathrm{l}$ of the solution was applied to a 60 TLC (Merck) silica gel plate with the aid of an automatic pipette. In addition to the sample to be analyzed, equal amounts of the triolein, diolein, monoolein, fatty acid, ergosterol and cholesteryl oleate were applied to the plates for comparison and quantification.

To ensure efficient separation and obtain acute bands of nonpolar lipids, the separation was performed as described below. First, the solvent mixture composed of petroleum ether/diethyl ether/acetic acid (70:30:2 v/v) was used to separate the lipids, until reaching $2 / 3$ the height of the silica plate $(7 \mathrm{~cm})$. After drying the plate, the separation continues in the same direction using the solvent mixture composed of petroleum ether/diethyl ether $(100: 2 \mathrm{v} / \mathrm{v})$ until it reaches the top of the plate $(9 \mathrm{~cm})[25]$.

The chromatographic plate after elution was revealed with iodine vapor and the stain retention ( $\mathrm{Rf}$ ) factor of the standards and sample components was determined.

To achieve an irreversible staining of nonpolar lipids and sterols in the TLC plate, it was kept in a solution of $0.63 \mathrm{~g}$ of $\mathrm{MnCl}_{2} 4 \mathrm{H}_{2} \mathrm{O}, 60 \mathrm{~mL}$ of water, $60 \mathrm{~mL}$ of methanol and $4 \mathrm{~mL}$ of sulfuric acid for 10 seconds, followed by heating to $105^{\circ} \mathrm{C}$. The intensity of the color depends on the heating time, which must be a minimum of $30 \mathrm{~min}$. With the aid of the Image Master Total Lab version 1.11 program, was used to identify and quantify the lipid classes present in the extracts.

\section{Results and Discussion}

\subsection{Lipid Content of the Biomass of Scenedesmus sp.}

The average values obtained in the extraction of lipids, following the different solvents/methods, are presented in Figure 2 and were expressed as a percentage in relation to the dry biomass mass free of ash.

The lipids showed statistically significant differences $(p<0.05)$. The lipid contents reached via extraction without chemical treatment (only with the use of solvents) were higher when compared to those obtained with the results via chemical treatment. This behavior can be partially explained due to the presence 


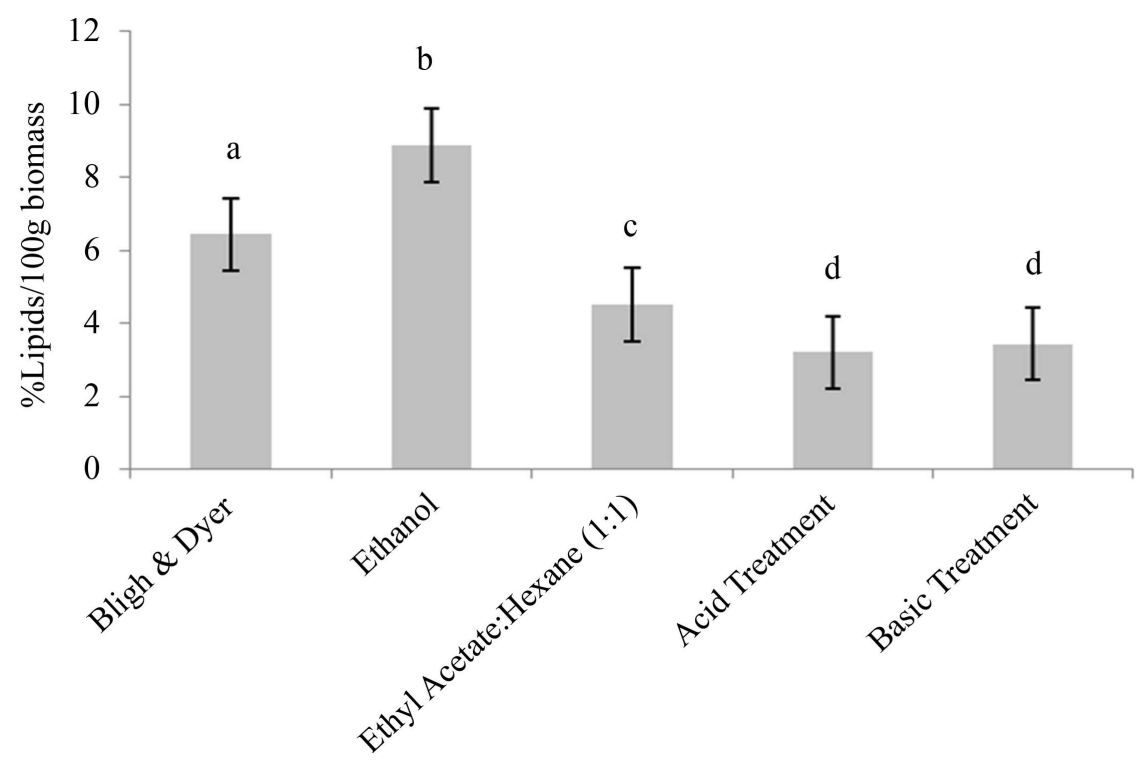

Figure 2. Lipid content of microalgae Scenedesmus sp. ${ }^{\star}$ The values calculated based on triplicates of experiments. Different letters differ statistically from each other.

of neutral lipids inside the cell, which bind strongly to proteins located in the cell membrane, via hydrogen bonds, forming a complex with polar lipids. Van der Waals interactions between the nonpolar solvent and lipids are not able to break this membrane, based on lipid-protein associations. Polar solvents, such as methanol or ethanol, break these associations, forming hydrogen bonds with the polar lipids in the complex. In addition, the use of polar solvents such as acetone, ethanol, methanol increases the affinity for pigments, sugars, and polar lipids, leading to an increase in these compounds in the extract [33]. Therefore, the addition of a polar solvent facilitates the extraction of neutral lipids associated with the membrane. However, the use of more polar solvents leads to overestimated total lipid yields, when compared to methods using less polar solvents, as in the case of the ethyl acetate:hexane mixture $(1: 1 \mathrm{v} / \mathrm{v})$. The content of lipids obtained by the acid treatment of biomass $(3.21 \% \pm 0.32 \%)$ was statistically equal to that obtained in the basic treatment $(3.44 \% \pm 0.28 \%)$. When biomass was applied with an acid or basic treatment, there was a reduction of $49.84 \%$ and $53.41 \%$, respectively, in the amount of lipids extracted when compared to that obtained via solvent, chloroform:methanol, 2:1 v/v—Bligh \& Dyer [28].

\subsection{Identification of Lipid Components-Thin Layer Chromatography}

For the identification of the lipid classes present in the extracts, obtained by the different methods evaluated in this work, the thin layer chromatography technique was used. The main objective of this identification was to select more selective extraction procedures for the fatty compounds of interest for the production of biofuels [34]. As it was possible to verify in Figure 3, the extracts presented fatty acids, triglycerides, diglycerides, sterols and carotenoids identified according to with $\operatorname{Rf}$ (Retention Factor) - order of elution of each compound. 


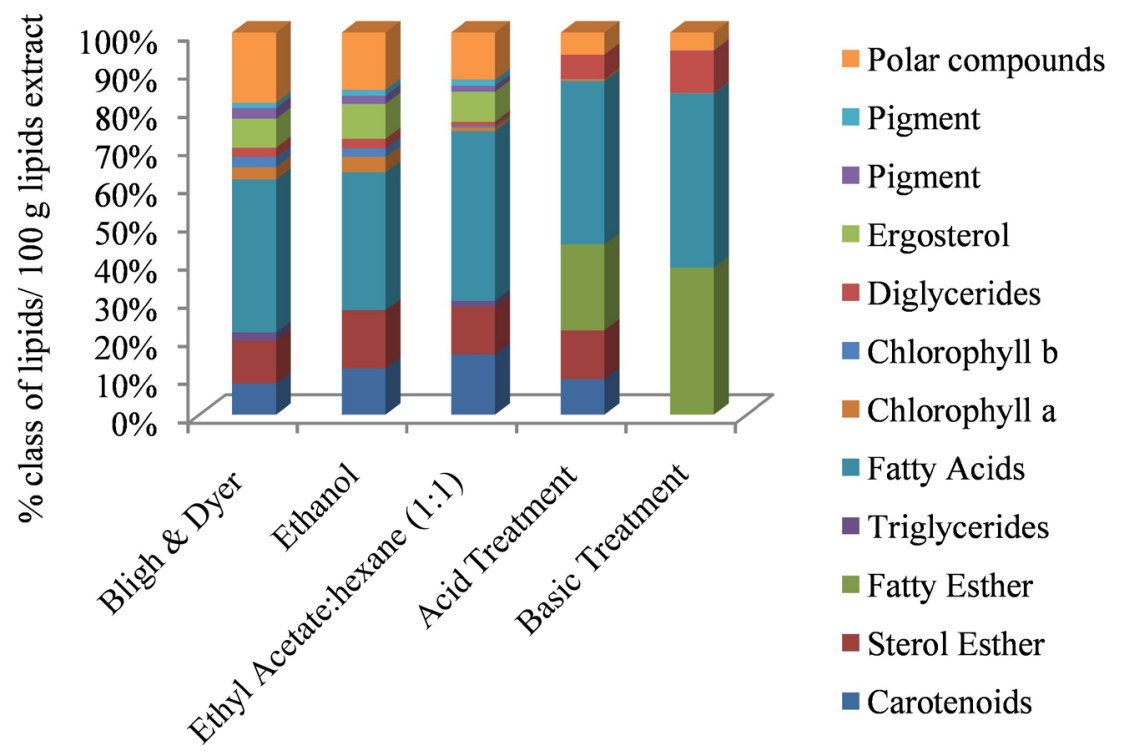

Figure 3. Main lipid classes present in extracts.

Performing a detailed analysis of the main fatty components present in lipid extracts it is possible to verify that, even when methods without chemical conversion are used, the triglyceride content was low and did not exceed $2.1 \%$ as in the case of Bligh \& Dyer. The Scenedesmus sp. evaluated in our work showed a reduced amount of triglycerides when compared to conventional oilseeds used for biodiesel production. Conventional oilseeds such as palm, soy and sunflower have amounts greater than $90 \%$ of triglycerides in the oil [34].

The triglyceride content present in Scenedesmus sp. evaluated in our work was also inferior to those reported for the microalgae Parietochloris incisa, which presented $42.9 \%$ and for Pavlova lutheri with 40.3\% [35]. For Scenedesmus sp. reported by Keyun [36] the content of triglycerides did not exceed $4.1 \%$ in the lipid extract. Even with a lower than expected concentration of triglycerides, it was possible to confirm that the use of a solvent/method without chemical conversion in obtaining lipid extracts allows verifying the accumulation of triglycerides (in their original form) in the microalgae biomass. Still with a low content of triglycerides in the lipid extract, obtained with ethyl acetate:hexane $(1: 1 \mathrm{v} / \mathrm{v})$, the presence of up to $44.35 \%$ of free fatty acids was identified. This result confirms that some factors influenced the low concentration of triglycerides in the samples. The presence of phospholipids present in the structural lipids of microalgae may have contributed to the increase in fatty acids, as they function as pro-hydrolyzing agents. The amount of water present in the biomass after collection ( $85 \%$ humidity) and the time of 24 hours, associated with a temperature of $100^{\circ} \mathrm{C}$ performed in the drying of the biomass, probably contributed to the hydrolysis of the triglycerides, increasing the amount of free fatty acids. In addition, during the cultivation of Scenedesmus sp. biomass, chlorophyll can undergo the photooxidation process generating $\mathrm{O}^{-2}$ radicals in the cell that can promote the degradation of lipids [37]. The microalgae Phaeodactylum tricor- 
nutum also showed high levels of free fatty acids, which probably resulted from lipid degradation during the storage and processing time of the biomass [38]. According to Ryckebosch [38], when storing microalgae biomass in nature, with high amount of water and without any type of enzymatic inactivation, lipolysis occurs naturally.

As can be seen by thin layer chromatography plates, the methods and solvents used in extracting the lipids from Scenedesmus sp. they did not include only fatty components. Pigments and sterols were observed (Figure 3 ). In the lipid extracts obtained via Bligh \& Dyer, Ethanol and Ethyl acetate:hexane (1:1 v/v) the presence of green pigments was observed, mainly chlorophylls a and b. The use of polar solvents such as acetone, ethanol, methanol increases the affinity of these molecules with the solvent, causing an increase of these compounds in the extract [33]. In extracts that underwent chemical treatment, such as J-Schmid-Bondzynski-Ratzlaff and saponification, the presence of chlorophylls was reduced (Figure 3 ). During acid hydrolysis by the addition of $\mathrm{HCl}$, the presence of available $\mathrm{H}^{+}$in the reaction medium reacts with the chlorophyll present in the biomass. This phenomenon is known as pheophytinization, where the magnesium in the center of the chlorophyll molecule reacts with $\mathrm{H}^{+}$and is replaced by hydrogen, changing the color of the extract from green to brown. Another common type of chlorophyll reaction is in the presence of $\mathrm{OH}^{-}$in the medium, where the phytol chain is removed, leading to the formation of chlorophyll or pheoforbid [39], making this pigment sparingly soluble in organic solvents and highly soluble in water.

The presence of polar components reached up to $18.41 \%$, as in the case of lipid extract obtained via Bligh \& Dyer. The decrease in the amount of polar lipids in the extracts of $J$-Schmid-Bondzynski-Ratzlaff and saponification can be explained due to the presence of $\mathrm{OH}^{-}$and $\mathrm{H}^{+}$, respectively, in these procedures. Chemical treatment contributed to the hydrolysis and esterification of complex lipids such as phospholipids and glycolipids in fatty acids and fatty esters, respectively [40] [41].

In the extract produced via saponification, $38.48 \%$ of ethyl esters (biodiesel) were observed (Figure 3 ). The presence of these compounds was also identified in the extract obtained via J-Schmid-Bondzynski-Ratzlaff, but in a smaller amount $(22.53 \%)$. It is known that the presence of water in the reaction medium, can inhibit the esterification reaction. The ethyl esters formed come from the transesterification/esterification reaction of triglycerides and fatty acids through the presence of ethanol and catalyst (acid or basic). The direct saponification of biomass can be an interesting process for the production of biodiesel since it eliminates the lipid extraction step; however a greater amount of chemical inputs may be necessary.

The lipid extracts obtained via solvent (without chemical treatment), showed a large amount of unsaponifiable compounds such as: sterols, carotenoids and pigments, demonstrating that only the use of organic solvents was not selective to obtain fatty components. In this sense, a chemical refining of these extracts 
(via saponification) would be necessary to increase the final concentration of fatty components. Still in the sample extracted with acid hydrolysis of biomass, as in the case of the J-Schmid-Bondzynski-Ratzlaff method, the presence of sterols (12.98\%) and carotenoids (9.37\%) was observed. According to the literature [35] [38] [39], there is a high lipophilic affinity of sterols to the solvents petroleum ether, hexane and ethyl acetate. Sterols are important constituents of the cell membranes of eukaryotic organisms, being intertwined with phospholipid bilayers. The amount of sterols present in the biomass of Scenedesmus sp. it can be considered high, when compared with other raw materials such as corn, which presents $0.8 \%$ of total sterols in oil [38] [39]. A detailed analysis of the composition of the sterols present in the extracts was not carried out, as the work focused only on the components that can be converted into biofuels. As the unsaponifiable fraction cannot be converted into biodiesel, sterols and carotenoids can be separated, purified and used as products with high added value.

Figure 4 shows the percentages of fatty and non-fatty compounds present in each of the extracts. As fatty components, fatty esters, triglycerides, fatty acids and diglycerides were considered. The percentage of non-fatty compounds was determined by difference in relation to the total fatty compounds.

The lipid extracts obtained from the extraction via solvents presented between $38.58 \%$ and $46.86 \%$ of fatty material (saponifiable) while those obtained through chemical treatment presented between $71.47 \%$ and $94.99 \%$. In Figure 5, it was possible to evaluate the different methods used to obtain the lipids in relation to the amount of saponifiable material (fatty) generated from 100 grams of dry biomass of Scenedesmus sp.

The amount of fatty material did not exceed 3.43\%, this result being lower when we consider conventional oilseeds, such as soybeans, the main raw material for the production of biodiesel in Brazil, which has an average of $18 \%$ oil. The

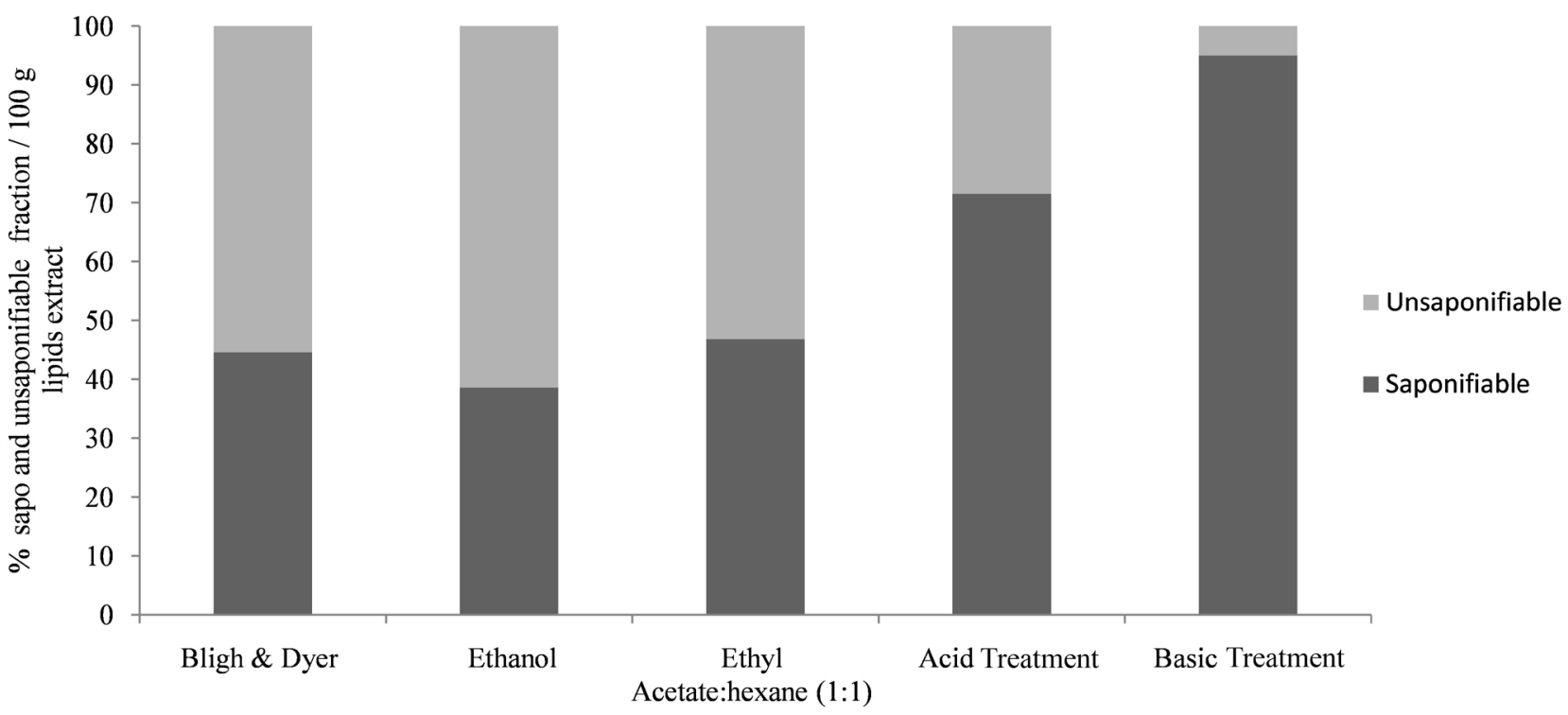

Figure 4. Percentage of fatty and non-fatty components in lipid extracts. 


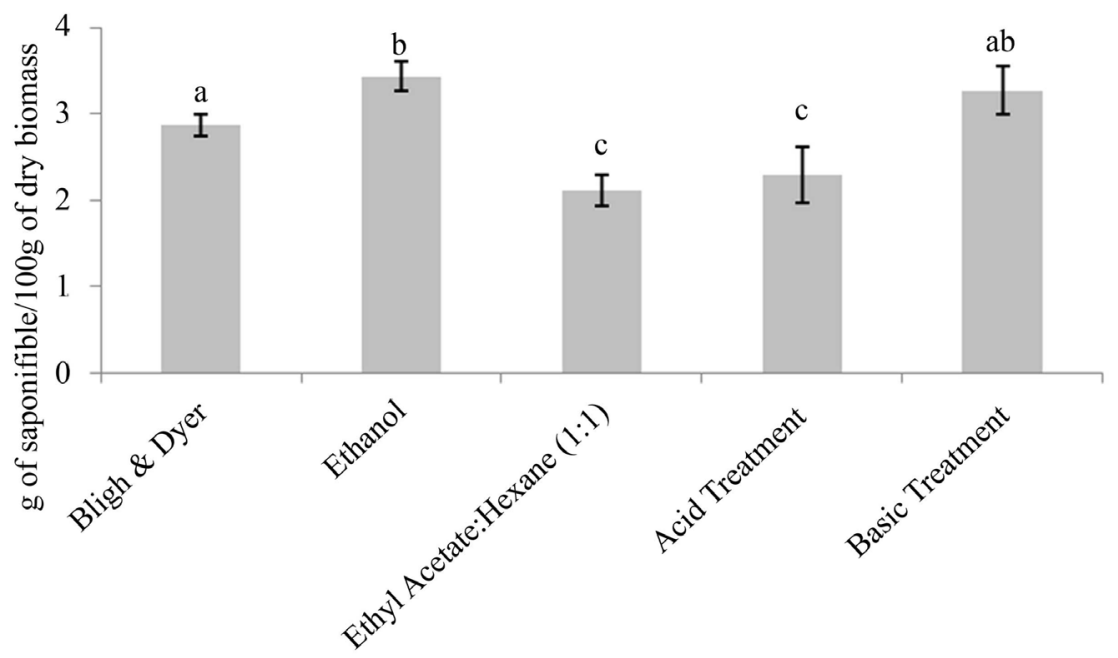

Figure 5. Percentage of fatty material/100 grams of dry biomass Scenedesmus sp. ${ }^{*}$ The values calculated based on triplicates of experiments. Different letters differ statistically from each other.

method of Bligh \& Dyer and Ethanol presented amounts of fatty material statistically equal to those obtained by the basic treatment method (saponification in situ). However, using only solvents, an additional step must be taken for the concentration and purification of the fatty material for the production of biofuels.

\section{Conclusions}

From 100 grams of dry biomass of Scenedesmus sp. by the methods of Bligh \& Dyer and Ethanol it was possible to obtain the same amount of saponifiable material (fat) as that obtained by the basic treatment (saponification in situ) $3.27 \%$ $\pm 0.28 \%$.

The lipids contents of Scenedesmus sp., obtained via solvent extraction/method without chemical conversion, were up to $53 \%$ by weight higher than those obtained via chemical treatment of biomass. However, the extraction without chemical conversion, using only solvents, led to the co-extraction of other non-fatty (unsaponifiable) components that overestimated the results. Among the unsaponifiable components present in these extracts, carotenoids, pigments and sterols were identified. The increase in the polarity of the solvent used in the extraction led to an increase in the amount of pigments extracted. In lipid extracts obtained without chemical conversion, fatty acid (44.5\%) was the main component. While triglycerides $(<2.1 \%)$ were the minority component. The use of lipid extraction methodologies without chemical conversion, only with the use of solvents, allowed verifying the disposition of the lipid classes in full form. To obtain a fraction rich in fatty components, the extracts will require an additional chemical refining step to separate saponifiable and unsaponifiable.

The chemical treatment methodologies applied to biomass, J:Schmid-Bondzynski-Ratzlaff and saponification, showed the same amount of extracted lipids 
$3.21 \% \pm 0.32 \%$ and $3.44 \% \pm 0.28 \%$, respectively. The presence of ethyl esters was detected in a concentration of up to $38.48 \%$ in the lipid extract obtained via saponification in situ of the biomass. The chemical treatment of biomass resulted in the conversion of the most complex lipids into free fatty acids. Among the methods evaluated in this study, the basic hydrolysis of biomass via saponification, was proved to be the most selective to obtain a $94.99 \%$ grease fraction. Therefore, starting from a lipid fraction, with a more homogeneous composition in fatty components, the definition of the technological route to be applied in its conversion into biofuels will be facilitated.

\section{Acknowledgements}

We thank the CENPES/Petrobras/ANP for the financial support, the GREENTEC Laboratory (UFRJ) for their support in the research, to the Federal University of Viçosa for the supply of microalgae biomass and to the financial agency (FAPERJ) for the support given.

\section{Conflicts of Interest}

The authors declare no conflicts of interest regarding the publication of this paper.

\section{References}

[1] Show, K., Lee, D., Tay, J., Lee, T. and Chang, J. (2015) Microalgal Drying and Cell Disruption-Recent Advances. Bioresource Technology, 184, 258-266. https://doi.org/10.1016/j.biortech.2014.10.139

[2] Zhu, F.F., Zhao, L.Y., Jiang, H.M., Zhang, Z.L., Xiong, Y.Q., Qi, J.J. and Wang, J.W. (2014) Comparison of the Lipid Content and Biodiesel Production from Municipal Sludge Using Three Extraction Methods. Energy Fuels, 28, 5277-5283. https://doi.org/10.1021/ef500730c

[3] Huerlimann, R., Nys, R. and Heimann, K. (2010) Growth, Lipid Content, Productivity, and Fatty Acid Composition of Tropical Microalgae for Scale-Up Production. Biotechnology and Bioengineering, 107, 245-257. https://doi.org/10.1002/bit.22809

[4] Wu, L.F., Chen, P.C., Huang, A.P. and Lee, C.M. (2011) The Feasibility of Biodiesel Production by Microalgae Using Industrial Wastewater. Bioresource Technology, 113, 14-18.

[5] Certik, M. and Shimizu, S. (1999) Biosynthesis and Regulation of Microbial Polyunsaturated Fatty Acid Production. Journal of Bioscience and Bioengineering, 87, 1-14. https://doi.org/10.1016/S1389-1723(99)80001-2

[6] Singh, J. and Gu, S. (2010) Commercialization Potential of Microalgae for Biofuels Production. Renewable and Sustainable Energy Reviews, 14, 2596-2610. https://doi.org/10.1016/j.rser.2010.06.014

[7] Kruger, J.S., Christensen, E.D., Dong, T., Van Wychen, S., Fioroni, G.M., Pienkos, P.T. and McCormick, R.L. (2017) Bleaching and Hydroprocessing of Algal Biomass-Derived Lipids to Produce Renewable Diesel Fuel. Energy Fuels, 31, 10946-10953. https://doi.org/10.1021/acs.energyfuels.7b01867

[8] Bolonio, D., Llamas, A., Rodríguez-Fernandez, J., Al-Lal, A.M., Canoira, L., Lapuerta, M. and Gomez, L. (2015) Estimation of Cold Flow Performance and Oxida- 
tion Stability of Fatty Acid Ethyl Esters from Lipids Obtained from Escherichia coli. Energy Fuels, 29, 2493-2502. https://doi.org/10.1021/acs.energyfuels.5b00141

[9] Yang, F.F., Cheng, C.H., Long, L.J., Hu, Q.J., Jia, Q.K., Wu, H.L. and Xiang, W.Z. (2015) Extracting Lipids from Several Species of Wet Microalgae Using Ethanol at Room Temperature. Energy Fuels, 29, 2380-2386. https://doi.org/10.1021/ef5023576

[10] Borges, Fernanda Cabral. Proposta de um modelo conceitual de biorrefinaria com estrutura descentralizada (2010) Tese de doutorado. Escola de Engenharia Química. Universidade Federal do Rio Grande do Sul.

[11] Borges, L., de Faria, B.M., Odebrecht, C. and Abreu, P.C. (2007) Potencial de absorção de carbono por espécies de microalgas usadas na aquicultura: Primeiros passos para o desenvolvimento de um mecanismo de desenvolvimento limpo. Atlântica, Rio Grande, 29, 35-46.

[12] Yoo, C., Jun, S.Y. and Lee, J.Y. (2010) Selection of Microalgae for Lipid Production under High Levels Carbon Dioxide. Bioresource Technology, 101, S71-S74. https://doi.org/10.1016/j.biortech.2009.03.030

[13] Khan, S.A., Rashmi, M.Z.H., Prasad, S. and Banerjee, U.C. (2009) Prospects of Biodiesel Production from Microalgae in India. Renewable and Sustainable Energy Reviews, Amsterdam, 13, 2361-2372. https://doi.org/10.1016/j.rser.2009.04.005

[14] Lourenço, S.O. (2006) Cultivo de Microalgas Marinhas: Princípios e Aplicações. In: Embrapa Agroenergia, Rima, São Carlos, 606 p.

[15] Derner, R.B., Ohse, S., Villela, M., Carvalho, S.M. and de Fett, R. (2006) Microalgas, produtos e aplicações. Ciência Rural, 36, 1959-1967. https://doi.org/10.1590/S0103-84782006000600050

[16] Li, Y., Liu, H., Xiao, K.X., Jin, M.H., Xiao, H. and Yao, H. (2020) Combustion and Pyrolysis Characteristics of Hydrochar Prepared by Hydrothermal Carbonization of Typical Food Waste: Influence of Carbohydrates, Proteins, and Lipids. Energy Fuels, 34, 430-439. https://doi.org/10.1021/acs.energyfuels.9b02940

[17] Teri, G., Luo, L.G. and Savage, P.E. (2014) Hydrothermal Treatment of Protein, Polysaccharide, and Lipids Alone and in Mixtures. Energy Fuels, 28, 7501-7509. https://doi.org/10.1021/ef501760d

[18] Díaz, G.C., Cruz, Y.R., Fortes, M.M., Viegas, C.V., Carliz, R.G., Furtado, N.C. and Aranda, D.A.G. (2014) Primary Separation of Antioxidants (Unsaponifiables) the Wet Biomass Microalgae Chlamydomonas sp. and Production of the Biodiesel. Natural Science, 6, 1210-1218. https://doi.org/10.4236/ns.2014.615108

[19] Viegas, C.V., Hachemi, I., Mäki-Arvela, P., Smeds, A., Aho, A., Freitas, S.P., Da Silva, G., Mesquita, C., Carbonetti, G., Peurla, M., Paranko, J., Kumar, N., Aranda, D. Gomes, A. and Murzin, D.Y. (2015) Algal Products beyond Lipids: Comprehensive Characterization of Different Products in Direct Saponification of Green Alga Chlorella sp. Algal Research-Biomass Biofuels and Bioproducts, 11, 156-164. https://doi.org/10.1016/j.algal.2015.06.014

[20] Brennan, L. and Owende, P. (2010) Biofuels from Microalgae-A Review of Technologies for Production, Processing, and Extractions of Biofuels and Co-Products. Renewable Sustainable Energy Reviews, 14, 557-577. https://doi.org/10.1016/j.rser.2009.10.009

[21] Doca, M.G.M., Viêgas, C.V., Lemões, J.S., Miyasaki, E.K., Morón-Villarreyes, J.A., Primel, E.G. and Abreu, P.C. (2011) Production of FAMEs from Several Microalgal Lipidic Extracts and Direct Transesterification of the Chlorella pyrenoidosa. Biomass \& Bioenergy, 35, 1533-1538. https://doi.org/10.1016/j.biombioe.2010.12.047 
[22] He, H., Rodgers, R.P., Marshall, A.G. and Hsu, C.S. (2011) Algae Polar Lipids Characterized by Online Liquid Chromatography Coupled with Hybrid Linear Quadrupole Ion Trap/Fourier Transform Ion Cyclotron Resonance Mass Spectrometry. Energy Fuels, 25, 4770-4775. https://doi.org/10.1021/ef201061j

[23] Clemmitt, R.H. and Chase, H.A. (2000) Immobilised Metal Affinity Chromatography of $\beta$ Galactosidase from Unclarified Escherichia coli Homogenates Using Expanded Bed Adsorption. Journal of Chromatography A, 874, 27-43. https://doi.org/10.1016/S0021-9673(00)00087-X

[24] Yap, W.B., Tey, B.T., Alitheen, N.B. and Tan, W.S. (2010) Purification of His-Tagged Hepatitis B Core Antigen from Unclarified Bacterial Homogenate Using Immobilized Metal Affinity Expanded Bed Adsorption Chromatography. Journal of Chromatography A, 1217, 3473-3480. https://doi.org/10.1016/j.chroma.2010.03.012

[25] Liu, P.L., Corilo, Y.E. and Marshall, A.G. (2016) Polar Lipid Composition of Biodiesel Algae Candidates Nannochloropsis oculata and Haematococcus pluvialis from Nano Liquid Chromatography Coupled with Negative Electrospray Ionization 14.5 T Fourier Transform Ion Cyclotron Resonance Mass Spectrometry. Energy Fuels, 30, 8270-8276. https://doi.org/10.1021/acs.energyfuels.6b01514

[26] Mascal, M. and Nikitin, E.B. (2010) Co-Processing of Carbohydrates and Lipids in Oil Crops to Produce a Hybrid Biodiesel. Energy Fuels, 24, 2170-2171. https://doi.org/10.1021/ef9013373

[27] Lee, Y.-K., Chen, W., Shen, H., Han, D., Li, Y., Jones, H.D.T., TimLin, J.A. and Hu, Q. (2013) Basic Culturing and Analytical Measurement Techniques. In: Handbook of Microalgal Culture: Applied Phycology and Biotechnology, John Wiley \& Sons, Ltd., Oxford, 37-68. https://doi.org/10.1002/9781118567166.ch3

[28] Bligh, G. and Dyer, W. (1959) A Rapid Method for Total Lipid Extraction and Purification. Canadian Journal of Bio-Chemistry and Physiology, 37, 911-917. https://doi.org/10.1139/059-099

[29] Li, Y., Naghdi, F.G., Garg, S., Adarme-vega, T.C., Thurecht, K.J., Ghafor, W.A., Tannock, S. and Schenk, P.M. (2014) A Comparative Study: The Impact of Different Lipid Extraction Methods on Current Microalgal Lipid Research. Microbial Cell Factories, 13, 14. https://doi.org/10.1186/1475-2859-13-14

[30] Freitas, L.S. (2007) Desenvolvimento de procedimentos de extração do óleo de sementes de uva e caracterização química dos compostos extraídos. 227f. Tese (Doutorado em Química). Universidade Federal do Rio Grande do Sul-UFRGS. Porto Alegre.

[31] Viêgas, C.V. (2010) Extração e caracterização dos lipídeos da microalga Chlorella pyrenoidosa visando à produção de ésteres graxos. Dissertação para obtenção do título de mestre, Programa de pós-graduação em química tecnológica e ambiental, FURG, Rio Grande, RS.

[32] Schmid-Bondzynski-Ratzlaff (2012) Extração e quantificação de lipídios em microalgas. Modificado pela Universidade Federal de Viçosa. Departamento de Tecnologia de Alimentos.

[33] Streit, N.M., Canterle, P., Liana, W.C., Marta, H.H. and Luísa, H. (2005) As Clorofilas. Ciência Rural, 35, 748-755. https://www.redalyc.org/articulo.oa?id=33135343 https://doi.org/10.1590/S0103-84782005000300043

[34] Tangy, A., Kumar, V.B., Pulidindi, I.N., Kinel-Tahan, Y., Yehoshua, Y. and Gedanken, A. (2016) In-Situ Transesterification of Chlorella vulgaris Using Carbon-Dot Functionalized Strontium Oxide as a Heterogeneous Catalyst under Microwave Ir- 
radiation. Energy Fuels, 30, 10602-10610.

https://doi.org/10.1021/acs.energyfuels.6b02519

[35] Georgi, P., Albena, I., Ivan, I. and Irina, V. (2012) A Critical Look at the Microalgae Biodiesel. European Journal of Lipid Science and Technology, 114, 103-111.

https://doi.org/10.1002/ejlt.201100234

[36] Wang, K.Y., Zhou, Y.J., Liu, H.W., Cheng, K., Mao, J.W., Wang, F.J., Liu, W.J., Ye, M.L., Zhao, Z.B. and Zou, H.F. (2015) Proteomic Analysis of Protein Methylation in the Yeast Saccharomyces cerevisiae. Journal of Proteomics, 114, 226-233. https://doi.org/10.1016/j.jprot.2014.07.032

[37] Mazalli, M.R., et al. (2006) HPLC Method for Quantification and Characterization of Cholesterol and Its Oxidation Products in Eggs. Lipids, 41, 615-622. https://doi.org/10.1007/s11745-006-5010-0

[38] Ryckebosch, E., Muylaert, K., Eeckhout, M., Ruyssen, T. and Foubert, I. (2011) Influence of Drying and Storage on Lipid and Carotenoid Stability of the Microalga Phaeodactylum tricornutum. Journal of Agricultural and Food Chemistry, 59, 11063-11069. https://doi.org/10.1021/jf2025456

[39] Martins, R.C. and Silva, C.L.M. (2002) Modelling Colour and Chlorophyll Losses of Frozen Green Beans (Phaseolus vulgaris. L.) Haricots verts congelés: Modélisation de la diminution de l'intensité de la couleur et de la teneur en chlorophylle. International Journal of Refrigeration, 25, 966-974.

https://doi.org/10.1016/S0140-7007(01)00050-0

[40] Vicente, S.J.V. and Torres, E.A.F.S. (2007) Formation PF Four Oxidation Products and Loss of Free Lipids, Cholesterol and Water in Beef Hamburgers as a Function of Thermal Processing. Food Control, 18, 63-68. https://doi.org/10.1016/j.foodcont.2005.08.009

[41] Santek, M.I., Lisicar, J., Musak, L., Spoljaric, I.V., Beluhan, S. and Santek, B. (2018) Lipid Production by Yeast Trichosporon oleaginosus on the Enzymatic Hydrolysate of Alkaline Pretreated Corn Cobs for Biodiesel Production. Energy Fuels, 32, 12501-12513. https://doi.org/10.1021/acs.energyfuels.8b02231 